\title{
Familial hypertrophic cardiomyopathy: vectorcardiographic findings in echocardiographically unaffected relatives
}

\author{
FRANCESCO LOPERFIDO, ROSARIO FIORILLI, ALESSANDRO DIGAETANO, MARCO \\ DI GENNARO, PIETRO SANTARELLI, FULVIO BELLOCCI, ELDA COPPOLA, PAOLO \\ ZECCHI
}

From the Department of Cardiology, Università Cattolica Sacro Cuore, Rome, Italy

SUMMARY The electrocardiographic and vectorcardiographic (Frank system) features of the first degree relatives of subjects with documented familial hypertrophic cardiomyopathy were analysed. A total of nine affected members and 29 relatives were examined in four families. The subjects were considered to be affected when the septal to free posterior wall thickness ratio exceeded 1.3 at M-mode echocardiography.

Four relatives had asymmetric septal hypertrophy. Among 25 relatives without evidence of asymmetric septal hypertrophy, two over 20 years and 10 under 20 years of age showed increased voltage of $Q R S$ anterior forces $\left(Q_{2}\right.$ amplitude greater than $\left.0.80 \mathrm{mV}\right)$ on the orthogonal electrocardiogram. The vectorcardiographic data of the relatives under 20 years of age without evidence of asymmetric septal hypertrophy (18 subjects) were compared with those of 38 normal control subjects of comparable age range. The young relatives without disproportionate septal hypertrophy had significantly greater $Q_{z}$ amplitude and $Q / R_{z}$ ratio than the normal control subjects. In contrast, the echocardiographic data were not significantly different.

We suggest that the electrocardiographic finding of abnormal anterior forces in one or more first degree relatives of subjects with documented hypertrophic cardiomyopathy may constitute a valuable aid in ascertaining the genetic transmission of the disease and in recognising affected members without echocardiographic evidence of hypertrophic cardiomyopathy.

Most investigators agree that in some cases hypertrophic cardiomyopathy is genetically transmitted..$^{1-3}$ This view has been drawn mainly from echocardiographic studies on the first degree relatives of subjects with documented hypertrophic cardiomyopathy. ${ }^{24}$ In these studies asymmetric septal hypertrophy was used as the diagnostic marker of the disease. ${ }^{14}$ Several authors, however, have recently questioned the reliability of M-mode echocardiography alone in making the diagnosis. ${ }^{5-10}$ Goodwin, ${ }^{11}$ for example, emphasised that a firm diagnosis of hypertrophic cardiomyopathy should rely on all clinical and laboratory data, including the history, clinical signs, electrocardiogram, cardiac catheterisation, angiography, and M-mode or two dimensional echocardiography. Furthermore, a positive family study may strongly support the diagnosis of genetically transmitted hypertrophic cardiomyopathy in a propositus with

Accepted for publication 4 February 1982 asymmetric septal hypertrophy. ${ }^{3-11}$

The electrocardiogram and vectorcardiogram have commonly been considered secondary aids in the identification or assessment of the severity of hypertrophic cardiomyopathy because they do not show specific abnormalities. ${ }^{12-21}$ Consequently, until now little attention has been focused on the electrocardiographic findings in the relatives of subjects with the disease. $^{2}$

In this study we report the electrocardiographic and vectorcardiographic findings in first degree relatives of subjects with documented familial hypertrophic cardiomyopathy, and their relation with M-mode echocardiographic data.

\section{Subjects and methods}

Four families were studied, in which two of more living first degree relatives had previous haemodynamic and angiographic evidence of hyper- 
trophic cardiomyopathy. Sudden deaths had occurred in one or more members of three families. All of the surviving members with previously documented hypertrophic cardiomyopathy (index cases) and their first degree relatives (parents, children, brothers, and sisters) were asked to co-operate in the study, which included a history, physical examination, standard 12 lead electrocardiograms, vectorcardiograms, and M-mode echocardiograms. Whenever possible, detailed information on the family members who had died or who did not co-operate (seven subjects) was collected.

Nine index cases (five male and four female, age range from 10 to 61 years, mean $40 \cdot 2 \pm 17 \cdot 3$ ) and 29 first degree relatives ( 15 male and 14 female, aged from 4 to 59 years, mean $15 \cdot 7 \pm 11 \cdot 1$ ) were examined. Of the first degree relatives, eight (two men and six women) were over 20 years and 21 ( 13 male and eight female subjects, aged from 4 to 20 , mean $11 \cdot 0 \pm 6 \cdot 3$ ) were under 20 years of age. The number of members examined for each family was as follows: family A, two index, three relatives; family $\mathrm{B}$, two index, 10 relatives; family $C$, three index, 11 relatives; family $\mathrm{D}$, two index, five relatives. The 38 control subjects were under 20 years (18 male and 20 female) without any clinical evidence of cardiovascular disease, and these were compared with those relatives who were younger than 20 years. Their ages ranged from 4 to 20 years, mean $9 \cdot 9 \pm 5 \cdot 5$.

\section{M-MODE ECHOCARDIOGRAPHY}

M-mode echocardiograms were recorded using a 2.25 $\mathrm{MHz}$ transducer of $1.5 \mathrm{~cm}$ diameter and $7.5 \mathrm{~cm}$ focal length connected to a modified Smith-Kline Echoline 20A. The output was displayed on a Cambridge strip-chart recorder. The paper speed was $50 \mathrm{~mm} / \mathrm{s}$. The examination was performed with the subject in a supine or left semilateral position, via the third or the fourth left intercostal space at the left sternal border.

The following echocardiographic measurements were obtained (Fig. 1). ${ }^{22}$ (1) The thickness of the interventricular septum, measured in diastole, at the first deflection of the QRS complex below the tips of the mitral valve leaflets using the leading edge method. (2) The left ventricular posterior wall thickness, measured at the level of the tips of the mitral valve during the same phase of cardiac cycle. (3) The left ventricular end-diastolic internal dimension, measured below the tips of the mitral valve leaflets at the peak of the onset of the $R$ wave. The septal thickness and left ventricular internal dimension were corrected by body surface. The degree of approximation
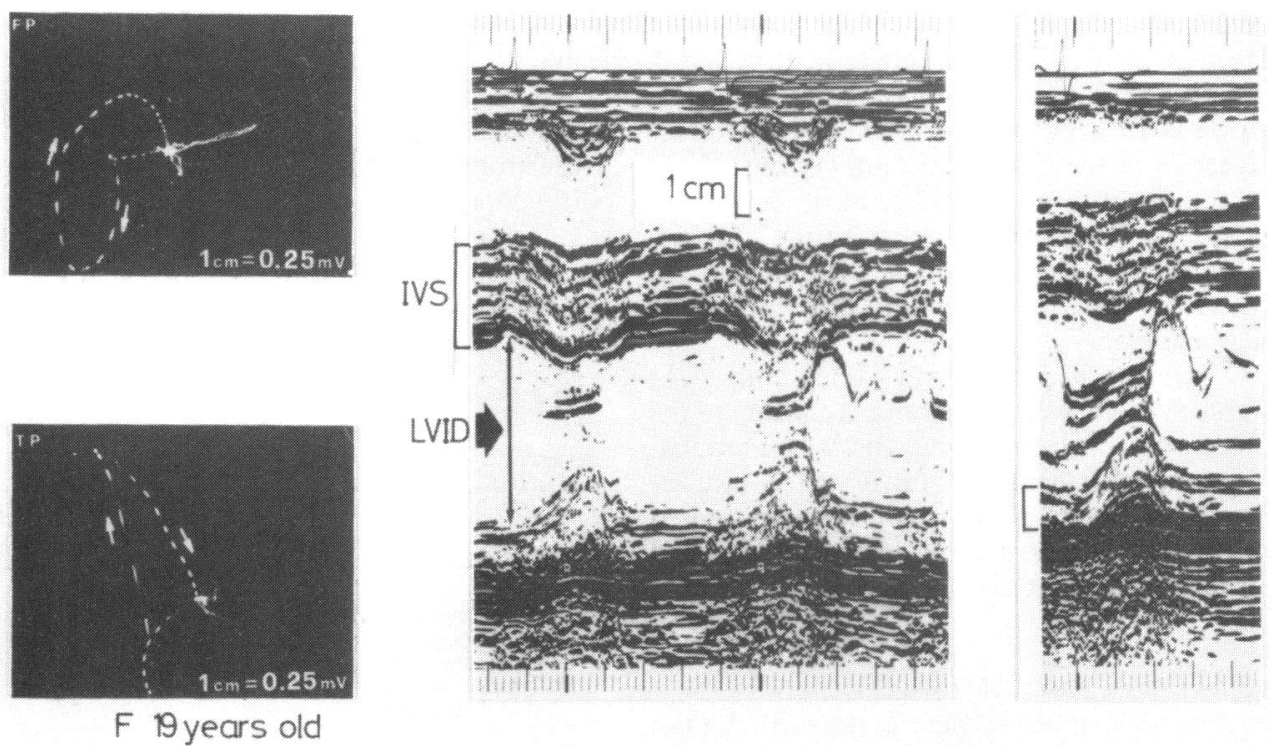

Fig. 1 The echocardiogram and vectorcardiogram of a 19-year-old woman with angiographically documented diagnosis of obstructive hypertrophic cardiomyopathy. Asymmetric septal hypertrophy is present on the M-mode echocardiogram. The vectorcardiogram shows an anteriorly displaced and rightward oriented QRS loop. IVS, interventricular septum; LVID, left ventricular end-diastolic interval dimension. 
of the anterior mitral valve leaflet to the ventricular septum, prominent systolic anterior movement of the mitral valve, and mid-systolic closure of the aortic valve were assessed.

Measurements of at least three cycles were averaged and separately measured by two investigators. When significant differences were present between the two observers, the final measurement was subjected to arbitration by a third.

Subjects were considered to have asymmetric septal hypertrophy when the septal to free posterior wall ratio was equal to or greater than $1 \cdot 3$. The interventricular septum thickness and end-diastolic left ventricular internal dimension were considered abnormal when they exceeded the normal corrected values. ${ }^{23}$

\section{VECTORCARDIOGRAPHY}

Vectorcardiograms were recorded using the Frank lead system with a 1507A Hewlett-Packard Vector Programmer, a Sanborn 760-6A VisoScope, and photographed with a Model 197A Option 05 Oscilloscope Camera. The records were obtained with the subject in the supine position. The thoracic electrodes were placed at the level of the fourth intercostal space. Orthogonal leads were recorded at a sweep speed of $250 \mathrm{~mm} / \mathrm{s}$. Frontal, transverse, and left sagittal planes were recorded in each subject. The loops were interrupted so that each dash represented $2.5 \mathrm{~ms}$. Standard notations were used for the localisation of vectors.

The following vectorcardiographic variables were considered: (1) QRS duration; (2) QRS rotation in each plane; (3) $Q, R$, and $S$ amplitude in $x, y$, and $z$; (4) $Q / R$ ratio in $z$ (anteroposterior forces ratio); $R / S$ ratio in $x$ (leftward-rightward forces ratio); (5) voltage and orientation of the $Q R S$ maximum vector in frontal and transverse plane; (6) voltage of the maximum leftward spatial vector, calculated from the formula: $\sqrt{x^{2}+y^{2}+z^{2}} ;$ (7) duration of QRS anterior forces; and (8) orientation of the $\mathrm{T}$ maximum vector in frontal and transverse planes.

Left ventricular hypertrophy and left and right bundle-branch block were diagnosed according to the conventional electrocardiographic and vectorcardiographic criteria. ${ }^{24}$ Abnormal $Q$ and $R$ waves, indicating a "pseudo-infarction" pattern, were diagnosed according to the standard electrocardiographic and vectorcardiographic. criteria of myocardial infarction. ${ }^{24}$

\section{STATISTICAL ANALYSIS OF DATA}

Standard statistical analyses were performed. Values expressed are means \pm 1 standard deviation (SD). The $t$ test was used to test the difference between two means. When the data were not normally distributed, a two-sample Wilcoxon-Mann-Whitney test was used. Comparing the vectorcardiographic data of the rela- tives under 20 years without asymmetric septal hypertrophy with the normal control subjects, the normal range of the vectorcardiographic measurements refers to the values within two standard deviations of the control group.

\section{Results}

\section{(A) ECHOCARDIOGRAPHIC DATA}

Asymmetric septal hypertrophy was present in all nine index cases. In these, ventricular septal thickness ranged from 13 to $32 \mathrm{~mm}$.

Four first degree relatives had asymmetric septal hypertrophy: one was a 52 year old man, brother of two affected sisters (family B), one a 20 year old man, son of an affected mother (family $\mathrm{C}$ ), and two were brothers, 10 and 18 years of age, of a 19 year old affected girl (family D).

Asymmetric septal hypertrophy was absent in 25 relatives. Eighteen of these subjects were under 20 years of age. Ten were male and eight female. Their ages ranged from 4 to 20 years, mean $10 \cdot 7 \pm 6 \cdot 0$.

The corrected thickness of the interventricular septum was abnormal in all the index cases. Three index subjects showed anterior systolic movement of the anterior mitral leaflet and mid-systolic closure of the aortic leaflets.

The corrected thickness of the interventricular septum was abnormal in three of four relatives with asymmetric septal hypertrophy. None of these showed abnormal movement of the mitral or aortic valve.

The echocardiographic measurements in the relatives under 20 years and without asymmetric septal hypertrophy are presented in Table 1 and compared with those of the normal control subjects. The echocardiographic data of the normal controls corresponded to data published for subjects of comparable age. ${ }^{23}$ No significant difference was found between

Table 1 Echocardiographic data in relatives under 20 years of age without asymmetric septal hypertrophy and in normal control subjects

\begin{tabular}{|c|c|c|c|}
\hline & $\begin{array}{l}\text { Relatives }<20 y \\
(n=18: M 10, F 8)\end{array}$ & $\begin{array}{l}\text { Control sub } \\
(n=38: M\end{array}$ & $P$ \\
\hline \multicolumn{4}{|l|}{$\begin{array}{l}\text { Age (y) } \\
\text { Echocardiographic } \\
\text { measurements }\end{array}$} \\
\hline IVS thickness & $7 \cdot 6 \pm 1 \cdot 1$ & $7 \cdot 4 \pm 1.0$ & NS \\
\hline IVS thickness corr & $5.0 \pm 0.8$ & $5.9 \pm 0.7$ & \\
\hline LVPW thickness & $7 \cdot 1 \pm 0.9$ & $7 \cdot 1 \pm 0.9$ & NS \\
\hline LVPW thickness corr & $5.4 \pm 0.8$ & $5.6 \pm 0.7$ & NS \\
\hline LVIDd & $42 \cdot 6 \pm 4 \cdot 1$ & $41 \cdot 0 \pm 4 \cdot 5$ & NS \\
\hline LVIDd corr & $33.0 \pm 4.5$ & $33 \cdot 6 \pm 5 \cdot 1$ & NS \\
\hline IVS/LVPW ratio & $1.0 \pm 0.12$ & $1 \cdot 0 \pm 0.10$ & IS \\
\hline
\end{tabular}

IVS, interventricular septum; LVPW, left ventricular posterior wall; $\stackrel{\mathbb{D}}{\Omega}$ LVIDd, left ventricular internal dimension at end-diastole; corr, $\underset{\text { corrected by body surface area. }}{\sigma}$
col 
the relatives under 20 years without asymmetric septal hypertrophy and the control subjects. The interventricular septal corrected thickness was within normal limits in all relatives without asymmetric septal hypertrophy. None of these had abnormal movement of the mitral or aortic valve.

(B) ELECTROCARDIOGRAPHIC AND VECTORCARDIOGRAPHIC DATA

\section{(1) Index cases}

Four of the nine index cases fulfilled the electrocardiographic and vectorcardiographic criteria of left ventricular hypertrophy with or without strain. Two cases showed abnormal $\mathbf{R}$ waves in the right precordial leads and an anteriorly displaced QRS loop in the vectorcardiogram. In one case, abnormal left axis deviation was present. Two subjects had negative $\mathrm{T}$ waves in left precordial leads.

\section{(2) Relatives with asymmetric septal hypertrophy}

Of the four relatives with increased thickness of the interventricular septum, one had a complete right bundle-branch block, one an incomplete left bundlebranch block, and one an abnormal QRS left axis deviation. The electrocardiogram and vectorcardiogram were normal in a fourth.

\section{(3) Relatives without asymmetric septal hypertrophy}

The vectorcardiographic data in the relatives over 20 years and without asymmetric septal hypertrophy are presented in Table 2. The electrocardiographic and vectorcardiographic measurements were within normal limits in five subjects. Two relatives had an anteriorly displaced QRS loop, that is a $Q$ amplitude in $z$ greater than $0.80 \mathrm{mV} .{ }^{25}$ In one of these the $R / S$ ratio in V1 and V2 was $>1 .{ }^{24}$

Of 18 relatives under 20 years without disproportionate septal hypertrophy, 13 had normal electrocardiograms. Four young relatives had an $\mathrm{R} / \mathrm{S}$ ratio in $\mathrm{V} 1$ and V2 greater than $1 \mathrm{~mm}$ and R V1 amplitude greater

Table 2 Vectorcardiographic data in relatives over 20 years of age without asymmetric septal hypertrophy (seven cases)

\begin{tabular}{|c|c|}
\hline $\begin{array}{l}\text { QRS duration (ms) } \\
\text { QRS inscription frontal plane } \\
\text { QRS inscription transverse plane } \\
\text { QRS MV orientation frontal plane (degree) } \\
\mathrm{Q}_{\mathrm{z}} \text { amplitude (mV) } \\
\mathrm{R}_{\mathrm{z}} \text { amplitude (mV) } \\
\mathrm{R}_{\mathrm{x}} \text { amplitude (mV) } \\
\text { Q/R ratio in } \mathrm{z} \\
\text { QRS MV voltage TP (mV) } \\
\text { QRS MV voltage FP (mV) } \\
\text { MLSV voltage (mV) } \\
\text { Anterior forces duration in TP (ms) }\end{array}$ & $\begin{array}{l}84 \cdot 5 \pm 11 \cdot 1 \\
C W 3, C C W 4 \\
C C W 7 \\
+31^{\circ} \pm 16 \\
0.55 \pm 0.40 \\
1.05 \pm 0.30 \\
1 \cdot 10 \pm 0.35 \\
0.50 \pm 0.30 \\
1 \cdot 40 \pm 0.45 \\
1 \cdot 54 \pm 0.54 \\
1.68 \pm 0.61 \\
25 \pm 7\end{array}$ \\
\hline
\end{tabular}

CW, clockwise; CCW, counterclockwise; MV, maximum vector; MLSV, maximum leftward spatial vector. than $7 \mathrm{~mm} .{ }^{24}$ Of these, three were older than 12 years. In one case abnormal left axis deviation of QRS was present. The vectorcardiographic data in the relatives under 20 years without asymmetric septal hypertrophy and in the young normal control subjects are presented in Table 3 . The relatives had a significantly greater $Q_{z}$ voltage $(p<0.01)$ and $Q / R$ ratio in $z$ $(p<0.05)$ than the normal control subjects.

The prevalence of vectorcardiographic abnormalities in the young relatives without asymmetric septal hypertrophy is presented in Table 4. Two standard deviations from the mean of measurements in the control group are considered the normal limit. The vectorcardiographic data in our control group were not significantly different from those already published. ${ }^{26}$ All vectorcardiographic measurements were within normal limits in seven of the 18 young relatives (39\%). Eleven young relatives without asymmetric septal hypertrophy had some vectorcardiographic abnormalities. Ten of these had $Q_{z}$ amplitudes greater than $0.80 \mathrm{mV}$ and they were distributed in all the families examined. The subdivision is presented in Table 4. Of these, only two had $Q / R$ ratio in $z$ greater than $1 \cdot 2$. The distribution of $Q_{z}$ amplitude in young relatives without asymmetric septal hypertrophy and in normal control subjects is presented in Fig. 2. Four young relatives had high voltage of the maximum leftward spatial vector. An abnormal superior orientation of the QRS maximum vector in the frontal plane was observed in three young brothers in family $\mathrm{C}$.

Vectorcardiographic patterns in three relatives under 20 years of age without disproportionate septal hypertrophy are presented in Fig. 3 for purpose of illustration.

\section{Discussion}

The electrocardiogram is abnormal in almost every case of hypertrophic cardiomyopathy. Left ventricular hypertrophy, abnormal $Q$ waves, or tall $R$ waves in right precordial leads, ST-T changes, and intraventricular conduction disturbances are the most frequent findings. ${ }^{12}$ None of these electrocardiographic abnormalities, however, is pathognomonic of hypertrophic cardiomyopathy. ${ }^{20}$ Some investigators described characteristic electrocardiographic or vectorcardiographic patterns in obstructive, ${ }^{12-16}$ non-obstructive, 1921 and apical ${ }^{27}$ forms of hypertrophic cardiomyopathy. A definite relation between the electrocardiographic features and the degree of septal hypertrophy or left ventricular outflow tract obstruction, ${ }^{12}$ however, has not been established. Consequently, electrocardiograms and vectorcardiograms have been considered secondary aids in the diagnosis of hypertrophic cardiomyopathy. 
Table 3 Comparison of vectorcardiographic features in first-degree relatives under 20 years of age and normal control subjects

\begin{tabular}{|c|c|c|c|}
\hline Vectorcardiographic variables & Relatives & Control subjects & $P$ \\
\hline $\begin{array}{l}\text { QRS duration } \\
\text { QRS inscription frontal plane } \\
\text { QRS inscription transverse plane } \\
\text { QRS MV orientation frontal plane } \\
Q_{z} \text { amplitude } \\
R_{z} \text { amplitude } \\
R_{x} \text { amplitude } \\
\text { Q/R ratio } \\
\text { QRS MV voltage transverse plane } \\
\text { QRS MV voltage frontal plane } \\
\text { MLSV voltage } \\
\text { Anterior forces duration }\end{array}$ & $\begin{array}{l}80.2 \pm 9.0 \\
\text { CW } 15, C C W 3 \\
\text { CCW } 18 \\
+40^{\circ} \pm 21^{\circ} \\
0.80 \pm 0.42 \\
1 \cdot 19 \pm 0.34 \\
1 \cdot 11 \pm 0.42 \\
0.79 \pm 0.36 \\
1.52 \pm 0.52 \\
1.54 \pm 0.56 \\
1.71 \pm 0.53 \\
29.9 \pm 6.8\end{array}$ & $\begin{array}{l}78 \cdot 2 \pm 10 \\
\text { CW } 37, " 8 " 1 \\
\text { CCW } 38 \\
+46^{\circ} \pm 13^{\circ} \\
0.52 \pm 0.17 \\
1 \cdot 12 \pm 0.40 \\
1 \cdot 12 \pm 0.38 \\
0.53 \pm 0.34 \\
1 \cdot 35 \pm 0.45 \\
1.47 \pm 0.57 \\
1.60 \pm 0.48 \\
27 \cdot 5 \pm 4 \cdot 2\end{array}$ & $\begin{array}{l}\text { NS } \\
- \\
\text { NS } \\
<0 \cdot 01 \\
\text { NS } \\
\text { NS } \\
<0 \cdot 05 \\
\text { NS } \\
\text { NS } \\
\text { NS } \\
\text { NS }\end{array}$ \\
\hline
\end{tabular}

$\mathrm{CW}, \mathrm{CCW}, \mathrm{MV}$, and MLSV as in Table 2; "8", inscription initially clockwise.

Table 4 Prevalence of vectorcardiographic abnormalities in relatives under 20 years of age without asymmetric septal hypertrophy

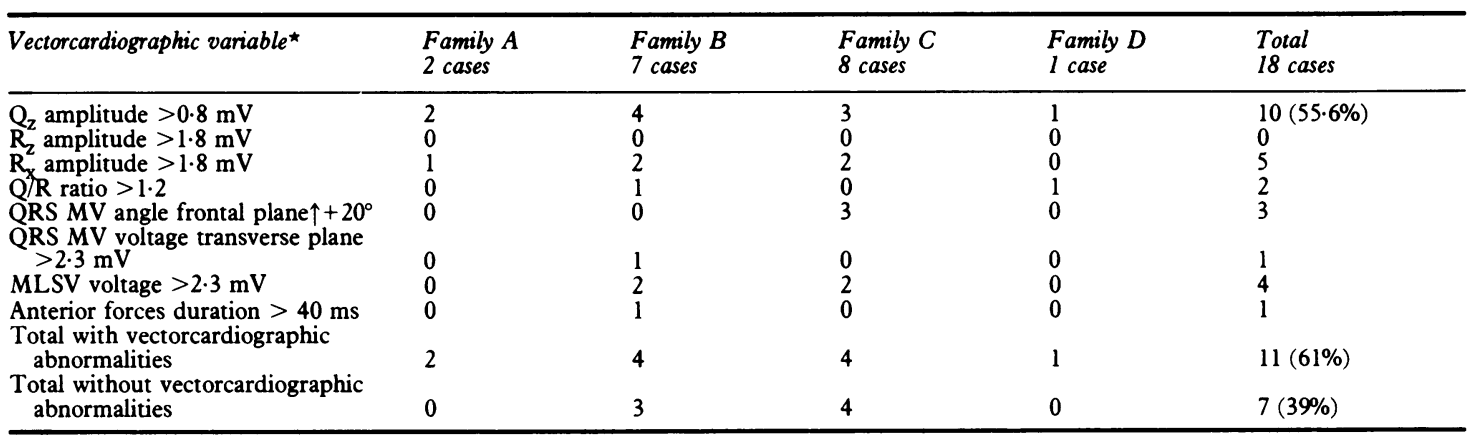

$\star 2$ SD from the mean of the vectorcardiographic measurements in the young normal control subjects are considered as normal limits.

Nevertheless, previous studies showed a high percentage of electrocardiographic abnormalities in those relatives where asymmetric septal hypertrophy was also found. ${ }^{2}$ On the other hand, few data have been reported on the electrocardiographic findings in relatives without asymmetric septal hypertrophy. The present study shows that a relatively large number of relatives of subjects with documented hypertrophic cardiomyopathy may have vectorcardiographic abnormalities, even though the echocardiogram is normal.

The most interesting observation is that ten out of 18 relatives under 20 years of age without asymmetric septal hypertrophy had increased voltage of the anterior forces on the orthogonal electrocardiogram $\left(Q_{z}\right.$ greater than $\left.0.80 \mathrm{mV}\right)$. Moreover, in each of the four families, at least one young relative who was considered to be unaffected on the basis of echocardiographic findings, had high amplitude of the anterior forces. Other abnormal and less commonly observed vectorcardiographic features included increased voltage of leftward $Q R S$ forces $\left(R_{x}\right.$ greater than $\left.1.8 \mathrm{mV}\right)$

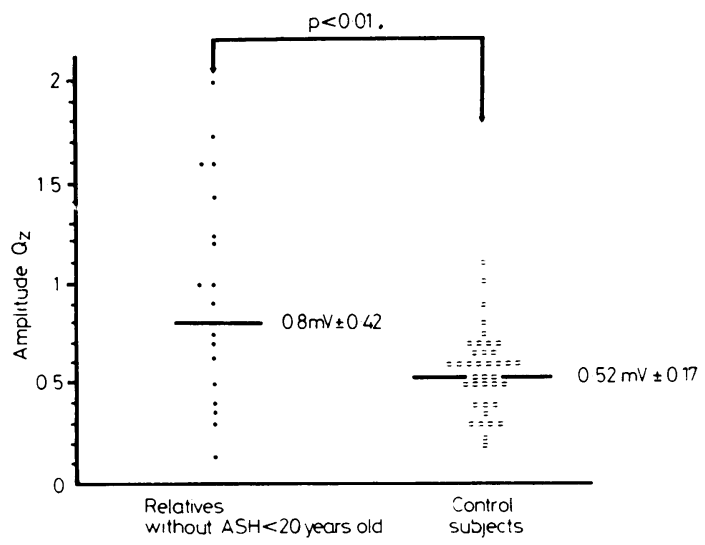

Fig. 2 The diagram shows the amplitude of the anterior forces of the $Q R S$ in the orthogonal electrocardiogram $\left(Q_{z}\right.$ voltage $)$ in the relatives under 20 years of age without asymmetric septal hypertrophy $(A S H)$ and in 38 normal control subjects of comparable age range. 
and pronounced superior orientation of QRS maximum vector in the frontal plane.

The standard electrocardiogram was within normal limits in 13 young relatives without disproportionate septal hypertrophy; this reflects a higher sensitivity of the vectorcardiogram in detecting increased $Q R S$ anterior forces. In fact, 11 young unaffected relatives showed vectorcardiographic abnormalities, but only one of them had increased voltage of $Q R S$ anterior forces.

The discrepancy between the electrovectorcardiographic and echocardiographic findings in so many relatives without asymmetric septal hypertrophy is difficult to explain.

First of all, the reliability of the diagnosis of asymmetric septal hypertrophy on the basis of the septal to free wall ratio ${ }^{328}$ is still controversial. It is well known that even minor errors in the measurement of the septal and posterior wall thickness may strongly influence the septal/posterior wall ratio, thereby hindering a correct classification of subjects with borderline ratios. ${ }^{2}$ In our study, however, none of the relatives classified as unaffected had clinical evidence of hypertrophic cardiomyopathy ${ }^{11}$ or had other abnormalities at $M$-mode echocardiography. ${ }^{28}$ Furthermore, concentric hypertrophy of the left ventricle, sometimes found in hypertrophic cardiomyopathy, ${ }^{272930}$ was absent in all cases.

On the other hand, an anterior displacement of the QRS loop may result from a variety of conditions such as right ventricular enlargement, ventricular preexcitation, right ventricular conduction defect, or true

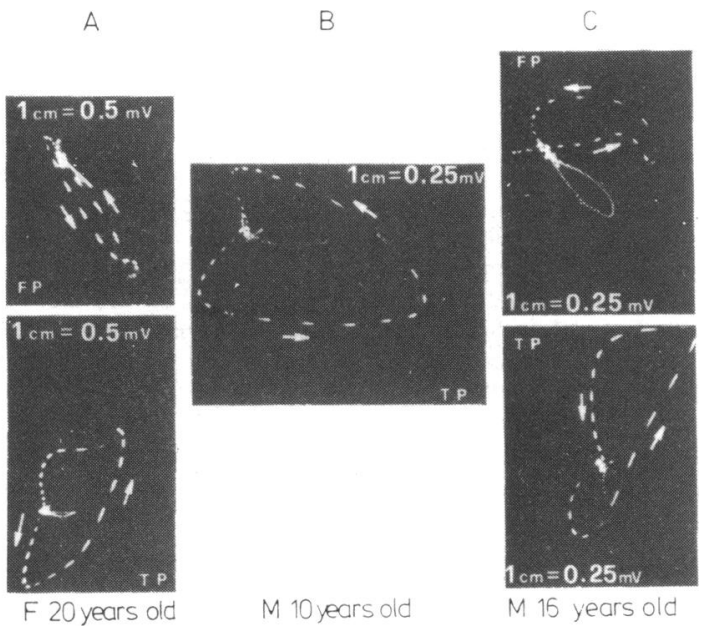

Fig. 3 Examples of vectorcardiographic patterns in relatives under 20 years of age without asymmetric septal hypertrophy. $(A)$ and $(B)$ increased voltage of the $Q R S$ anterior forces in the horizontal plane. (C) Abnormal superior orientation of the maximum vector of the $Q R S$ in the frontal plane. posterior myocardial infarction. ${ }^{21}$ Such a pattern has also been noted as a relatively common normal variant. ${ }^{19}$ All these causes, however, were excluded in our subjects on the basis of the clinical, electrocardiographic, and echocardiographic findings. In addition, the young relatives without asymmetric septal hypertrophy had increased amplitude of the anterior forces $(p<0.01)$ and greater anterior/posterior forces ratio $(\mathrm{p}<0.05)$ compared with normal controls, though the echocardiographic data were not significantly different. Thus, in this study the vectorcardiographic features observed in the young relatives without asymmetric septal hypertrophy should be considered as true abnormalities.

M-mode echocardiography is commonly considered a sensitive means for the identification of hypertrophic cardiomyopathy. ${ }^{28}$ One must be cautious, however, in diagnosing or excluding the disease by M-mode echocardiography alone. ${ }^{31}$ DeMaria et al. ${ }^{32}$ emphasised that wide angle two dimensional echocardiography may decrease the false positive diagnoses of asymmetric septal hypertrophy and may recognise unusual locations of left ventricular hypertrophy, such as the predominant concentric hypertrophy in the apex reported by Yamaguchi et al. ${ }^{27}$ Maron et al. ${ }^{29}$ recently reported other unusual locations of hypertrophic cardiomyopathy undetectable by M-mode echocardiography. In these cases the electrocardiogram was abnormal and represented a more sensitive marker than $M$-mode echocardiography. ${ }^{29}$ Consequently, hypertrophic cardiomyopathy should not be ruled out on the basis of $\mathrm{M}$-mode echocardiography alone when other clinical data suggest the diagnosis. ${ }^{29}$

For ethical reasons we did not perform invasive investigations on the relatives who did not show echocardiographic abnormalities. Unfortunately, two dimensional echocardiography was not obtained. Hence, in the absence of solid confirmatory data, we can only suggest alternative hypotheses to explain the significance of the vectorcardiographic abnormalities observed in the relatives without evidence of asymmetric septal hypertrophy.

First, these subjects could represent $\mathrm{M}$-mode echocardiographic false negatives of atypically distributed hypertrophic cardiomyopathy: hypertrophy of the posterior interventricular septum, the anterolateral free wall, or the apical portion of the septum, which were not detected by M-mode echocardiography, were present in $18 \%$ of the subjects reported by Maron et al. ${ }^{30}$

Second, the vectorcardiographic abnormalities could indicate an "occult" cardiomyopathy and precede the development of cardiac hypertrophy. This hypothesis is consistent with the data of Maron et $a l .,{ }^{30}$ who reported electrocardiographic abnor- 
malities in five young subjects with documented family history of hypertrophic cardiomyopathy and without any M-mode or two dimensional echocardiographic evidence of actual disease. ${ }^{29}$

Finally, increased voltage of QRS anterior forces may represent a marker not related to actual cardiac involvement in some familial forms of hypertrophic cardiomyopathy, as in relatives of subjects with Duchenne's progressive muscular dystrophy. ${ }^{33} 34$

On the other hand, the electrophysiological mechanism determining tall $R$ waves in the right precordial leads in many subjects with documented hypertrophic cardiomyopathy is still debated: either a disproportionate hypertrophy of the interventricular septum or a conduction disturbance of septal and apical areas could displace the QRS loop anteriorly and to the left. ${ }^{35} 36$ Conclusive evidence of a relation between this electrocardiographic feature and anatomical features of cardiomyopathy ${ }^{19}$ is, however, lacking.

Similarly, the clinical significance of abnormal anterior forces in the young relatives without asymmetric septal hypertrophy will probably be clarified only after follow-up. Moreover, definite conclusions cannot be drawn from the relatively small number of families examined.

In conclusion, we suggest that the observation of increased anterior QRS forces in one or more first degree relatives of a subject with documented hypertrophic cardiomyopathy may be a valuable aid in ascertaining the genetic transmission of the disease, complementing the echocardiographic data. ${ }^{37}$ The same feature might also be used to recognise affected or potentially affected members without echocardiographic evidence of asymmetric septal hypertrophy. ${ }^{29}$

We thank Mr Mario Iannarelli for technical and statistical assistance.

\section{References}

1 Clark CE, Henry WL, Epstein SE. Familial prevalence and genetic transmission of idiopathic hypertrophic subaortic stenosis. N Engl f Med 1973; 289: 709-14.

2 Van Dorp WG, Ten Cate FJ, Vletter WB, Dohmen H, Roelandt J. Familial prevalence of asymmetric septal hypertrophy. Eur $\mathcal{F}$ Cardiol 1976; 4: 349-57.

3 Maron BJ, Epstein SE. Hypertrophic cardiomyopathy: recent observations regarding the specificity of three hallmarks of the disease: asymmetric septal hypertrophy, septal disorganization and systolic anterior motion of the anterior mitral leaflet. Am $\mathcal{F}$ Cardiol 1980; 45: 141-54.

4 Henry WL, Clark CE, Epstein SE. Asymmetric septal hypertrophy. Echocardiographic identification of the pathognomonic anatomic abnormality of IHSS. Circulation 1973; 47: 225-33.

5 Larter WE, Allen HD, Sahn DJ, Goldberg SJ. The asymmetrically hypertrophied septum. Further differentiation of its causes. Circulation 1976; 53: 19-27.
6 Allen JW, Kim SJ, Edmiston WA, Venkataraman K. Problems in ultrasonic estimates of septal thickness. Am f Cardiol 1978; 42: 89-96.

7 Gibson DG, Traill TA, Hall RJC, Brown DJ. Echocardiographic features of secondary left ventricular hypertrophy. Br Heart f 1979; 41: 54-9.

8 Kansal S, Roitman D, Sheffield LT. Interventricular septal thickness and left ventricular hypertrophy. An echocardiographic study. Circulation 1979; 60: 1058-65.

9 Wei JY, Weiss JL, Bulkley BH. The heterogeneity of hypertrophic cardiomyopathy: an autopsy and one dimensional echocardiographic study. Am $\mathcal{f}$ Cardiol 1980; 45: 24-32.

10 Doi YL, Deanfield JE, McKenna WJ, Dargie HJ, Oakley CM, Goodwin JF. Echocardiographic differentiation of hypertensive heart disease and hypertrophic cardiomyopathy. Br Heart f 1980; 44: 395-400.

11 Goodwin JF. Hypertrophic cardiomyopathy: a disease in search of its own identity. Am $\mathcal{F}$ Cardiol 1980; 45: 17780.

12 Savage DD, Seides SF, Clark CE, et al. Electrocardiographic findings in patients with obstructive and nonobstructive hypertrophic cardiomyopathy. Circulation 1978; 58: 402-8.

13 Estes EH Jr, Whalen RE, Roberts SR Jr, McIntosh HD. The electrocardiographic and vectorcardiographic findings in idiopathic hypertrophic subaortic stenosis. Am Heart f 1963; 65: 155-61.

14 Walston A, II, Behar VS, Wagner GS, Greenfield JC Jr. Electrocardiographic and hemodynamic correlations in patients with idiopathic hypertrophic subaortic stenosis. Am Heart f 1976; 91: 11-7.

15 Prescott R, Quinn JS, Littmann D. Electrocardiographic changes in hypertrophic subaortic stenosis which simulate myocardial infarction. Am Heart f 1963; 66: 42-8.

16 Bahl OP, Walsh TJ, Massie E. Electrocardiography and vectorcardiography in idiopathic hypertrophic subaortic stenosis. Am f Med Sci 1970; 259: 262-71.

17 Brackbill TA, Shah PM. Vectorcardiographic comparison of left ventricular hypertrophy in idiopathic hypertrophic subaortic stenosis, aortic stenosis, and aortic regurgitation. Am Hear $\mathcal{F}$ 1974; 88: 269-76.

18 Maron BJ, Henry WL, Clark CE, Redwood DR, Roberts WC, Epstein SE. Asymmetric septal hypertrophy in childhood. Circulation 1976; 53: 9-19.

19 Chen C, Kawai C. Anterior QRS loop in hypertrophic cardiomyopathy. I Electrocardiol 1978; 11: 129-36.

20 Engler RL, Smith P, Lewinter M, Gosink B, Johnson A. The electrocardiogram in asymmetric septal hypertrophy. Chest 1979; 75: 167-73.

21 Chen CH, Nobuyoshi M, Kawai C. ECG pattern of left ventricular hypertrophy in nonobstructive hypertrophic cardiomyopathy. The significance of the mid-precordial changes. Am Heart $\mathcal{F}$ 1979; 97: 687-95.

22 Sahn DJ, DeMaria A, Kisslo J, Weyman A. Recommendations regarding quantitation in $\mathrm{M}$-mode echocardiography: results of a survey of echocardiographic measurements. Circulation 1978; 58: 1072-83.

23 Henry WL. Evaluation of older children and adults with congenital heart disease by $M$-mode and cross-sectional echocardiography. In: Roberts WC, ed. Congenital heart disease in adults. Philadelphia: F A Davis, 1979: 141-6. 
24 Friedman HH. Diagnostic electrocardiography and vectorcardiography. New York: McGraw Hill, 1977: 146, 181, 193, 284.

25 Draper HW, Peffer CJ, Stallmann FW, Littmann D, Pipberger HV. The corrected orthogonal electrocardiogram and vectorcardiogram in 510 normal men (Frank lead system). Circulation 1964; 30: 853-64.

26 Liebman J, Downs TD, Priede A. The Frank and $\mathrm{McFee}$ vectorcardiogram in normal children. In: Hoffman I, Hamby RY, Glassman E, eds. Vectorcardiography 2. Amsterdam: North Holland, 1971: 483-559.

27 Yamaguchi H, Ishimura T, Nishiyama S, et al. Hypertrophic nonobstructive cardiomyopathy with giant negative $\mathrm{T}$ waves (apical hypertrophy): ventriculographic and echocardiographic features in 30 patients. Am $\mathcal{F}$ Cardiol 1979; 44: 401-12.

28 Doi YL, McKenna WJ, Gehrke J, Oakley CM, Goodwin JF. M-mode echocardiography in hypertrophic cardiomyopathy: diagnostic criteria and prediction of obstruction. Am f Cardiol 1980; 45: 6-14.

29 Maron BJ, Gottdiener JS, Bonow RO, Epstein SE. Hypertrophic cardiomyopathy with unusual locations of left ventricular hypertrophy undetectable by $M$-mode echocardiography: identification by wide-angle twodimensional echocardiography. Circulation 1981; 63: 409-18.

30 Maron BJ, Gottdiener JS, Epstein SE. Patterns and significance of the distribution of left ventricular hypertrophy in hypertrophic cardiomyopathy: a wide-angle two-dimensional echocardiographic study of 125 patients. Am $\mathcal{F}$ Cardiol 1982; 48: 418-28.
31 Fowles RE, Martin RP, Popp RL. Apparent asymmetric septal hypertrophy due to angled interventricular septum. Am f Cardiol 1980; 46: 386-92.

32 DeMaria A, Bommer W, Lee G, Mason GT. Value and limitations of two dimensional echocardiography in assessment of cardiomyopathy. Am $\mathcal{F}$ Cardiol 1980; 46: 1224-31.

33 Ronan JA Jr, Perloff JK, Bowen PJ, Mann O. The vectorcardiogram in Duchenne's progressive muscular dystrophy. Am Heart $\mathcal{F}$ 1972; 84: 588-96.

34 Ishikawa $K$, Tamura $T$, Inoue $M$. Orthogonal electrocardiographic study on progressive muscular dystrophy of the Duchenne type. $\mathcal{F}$ Electrocardiol 1979; 12: 163-7.

35 Wigle ED, Baron RH. The electrocardiogram in muscular subaortic stenosis. Effect of a left septal incision and right bundle-branch block. Circulation 1966; 34: 585-94.

36 Van Dam RT, Roos JP, Durrer D. Electrical activation of ventricles and interventricular septum in hypertrophic obstructive cardiomyopathy. Br Heart f 1972; 34: 100 12.

37 Ten Cate FJ, Hugenholtz PG, Van Dorp WG, Roelandt $\mathrm{J}$. Prevalence of diagnostic abnormalities in patients with genetically transmitted asymmetric septal hypertrophy. Am $\mathcal{F}$ Cardiol 1979; 43: 731-7.

Requests for reprints to Dr Francesco Loperfido, Istituto di Cardiologia, Policlinico A Gemelli, Largo A Gemelli 8, 00168 Rome, Italy. 